\title{
Breast and Cervical Cancer Screening Behavior in Female Cancer Survivors: The Korea National Health and Nutrition Examination Survey, 2007-2012
}

\author{
Eun-Ae Lee', Jinyoung Shin ${ }^{1,2, *}$, Eun-Joo Hwang', Jung-Woong Lee' \\ 'Department of Family Medicine, Samsung Medical Center, Sungkyunkwan University School of Medicine, Seoul, Korea \\ ${ }^{2}$ Center for Cancer Supportive Care, Samsung Medical Center, Sungkyunkwan University School of Medicine, Seoul, Korea
}

\begin{abstract}
Background: The aim of this study was to compare breast and cervical cancer screening rates between female cancer survivors and a population without cancer to identify factors related to cervical and breast cancer screening in cancer survivors.

Methods: We included 17,765 adults (738 cancer survivors and 17,027 individuals without cancer) in this study, all of whom who were 30 years of age or older and participated in the Fourth and Fifth Korean National Health and Nutritional Examination Surveys from 2007-2012. Multiple logistic regression analysis was performed to identify factors related to cervical and breast cancer screening uptake in female cancer survivors.

Results: The screening rate for breast cancer was $56.6 \%$, which was higher than that in the non-cancer control group $(\mathrm{P}=0.001)$. The screening rate for cervical cancer was $51.4 \%$, which was not different from that of the noncancer control group. In terms of breast cancer screening, cancer survivors showed no significant difference in the rate of screening 5 years after their cancer diagnosis. However, cervical cancer survivors were less likely to have cervical cancer screening 10 years after their cancer diagnosis. There was no significant association between cancer screening and sociodemographic factors.

Conclusion: Breast and cervical cancer screening rates in Korean female cancer survivors are low. Secondary primary cancer screening of female cancer survivors needs to be planned in a comprehensive manner, with the consideration of influences beyond sociodemographic factors.
\end{abstract}

Keywords: Breast Neoplasms; Uterine Cervical Neoplasms; Early Detection of Cancer; Survivors 


\section{INTRODUCTION}

The number of cancer survivors is increasing because of early detection and advances in treatment. In Korea, 5-year relative cancer survival rates improved to $68.1 \%$ in $2008-2012$ from $41.2 \%$ in $1993-1995 .{ }^{1)}$

In cancer survivors, the diagnosis of a new cancer as a second primary cancer (SPC) is an important issue. ${ }^{2)}$ SPCs are a leading cause of mortality among long-term survivors and are more likely to occur in survivors. ${ }^{3,4)}$ Common etiologic factors such as lifestyle, environmental exposures, and genetics, as well as late effects of prior treatment, can influence SPC development. ${ }^{4)}$ Therefore, cancer survivors need to have more thorough and regular cancer screening than people without cancer. ${ }^{5-7)}$ However, the few studies that have provided SPC screening rates had limitations such as not considering the effect of sex or the cancer site, or having limited information about cancer sites. ${ }^{8-10)} \mathrm{Re}-$ search on SPC screening behavior in female cancer survivors is lacking. As the life expectancy of women increases, cancer incidence and cancer survival rates in women increase. In women, breast cancer is the second most common cancer in Korea. The age-standardized incidence rate of breast cancer in 2012 was 50.7 per 100,000 people, which represents a $5.9 \%$ annual increase since 1999. The age-standardized incidence rates for cervical cancer have continuously decreased in Korea, but they are higher than those in developed countries. ${ }^{1)}$ The National Cancer Screening Program (NCSP) provides women over 40 years of age with breast cancer screening and women over 30 years of age with cervical cancer screening biannually. ${ }^{11)}$ The NCSP set a goal of achieving a screening rate of $70 \%$ by $2015 .{ }^{12)}$ Although high cancer screening rates were expected, the SPC screening rate was only $37.7 \%$ in 2009, which is much lower than those in other developed countries. $^{13)}$

We investigated the screening rates for breast and cervical cancer in Korean female cancer survivors compared to women without cancer, and we investigated factors associated with breast and cervical cancer screening behavior.

\section{METHODS}

\section{Study Population}

Data were obtained from the fourth and fifth Korean National Health and Nutrition Examination Surveys (KNHANES), 2007-2012. KNHANES is a national representative survey that is carried out by the Korea Centers for Disease Control and Prevention. The survey includes approximately 10,000 individuals annually with data collected by multistage probability sampling. ${ }^{14,15)}$ Among 35,996 adults over 19 years of age, we selected 18,135 women who were 30 years of age or older. Participants were divided into two groups: cancer survivors and non-cancer controls. Cancer survivors were defined as those individuals reporting ever being diagnosed with any solid or hematologic cancer by a doctor. Among the remaining participants, we selected noncancer controls who were not diagnosed with any cancer. This study was approved by the institutional review board of Samsung Medical
Center (IRB no. 2015-12-020).

\section{Data Collection}

Screening behavior for breast and cervical cancer was obtained through self-reported questionnaires. Screening methods were defined as a mammogram or Papanicolaou test. The interval period of cancer screening was limited to within 2 years.

The sociodemographic variables included marital status, education level, household income, employment, and medical history of cancer or other comorbidities, which were obtained though face-to-face interviews. Health behaviors, such as smoking and alcohol use, were assessed using a self-administered questionnaire.

Education level was defined by the highest level achieved: less than high school, high school, or college and above. Monthly household income was classified according to quartiles: Q1 (lowest), Q2 (lower intermediate), Q3 (higher intermediate), or Q4 (highest). Smoking status was classified into 3 groups: never smoker, former smoker, or current smoker. Alcohol drinking status was defined as $\geq 1$ time $/$ mo or $<1$ time/mo. Comorbidity was defined as hypertension, hyperlipidemia,

Table 1. Baseline characteristics of female cancer survivors and non-cancer controls

\begin{tabular}{|c|c|c|c|}
\hline Characteristic & $\begin{array}{l}\text { Cancer survivors } \\
\qquad(\mathrm{N}=738)\end{array}$ & $\begin{array}{l}\text { Non-cancer controls } \\
\quad(\mathrm{N}=17,027)\end{array}$ & P-value* \\
\hline Age (y) & $57.2 \pm 0.6$ & $50.7 \pm 0.2$ & $<0.001$ \\
\hline Marital status & & & 0.207 \\
\hline Married & $75.6(71.4-79.3)$ & $78.1(77.2-78.9)$ & \\
\hline Divorced/separated/single & $24.4(20.7-28.6)$ & $21.9(21.1-22.8)$ & \\
\hline Education & & & $<0.001$ \\
\hline$<$ High school & $56.6(51.8-61.2)$ & $43.7(42.4-45.0)$ & \\
\hline High school & $29.9(25.7-34.4)$ & 33.7 (32.7-34.8) & \\
\hline$\geq$ College & $13.5(10.4-17.4)$ & $22.6(21.5-23.7)$ & \\
\hline Quartile of household income & & & 0.022 \\
\hline Q1 & 24.4 (20.9-28.3) & $19.7(18.7-20.7)$ & \\
\hline Q2 & $26.2(22.5-30.9)$ & $26.7(25.6-27.7)$ & \\
\hline Q3 & $21.9(18.3-25.9)$ & $27.3(26.4-28.2)$ & \\
\hline Q4 & $27.3(23.1-31.9)$ & $26.4(25.1-27.6)$ & \\
\hline Employment & & & $<0.001$ \\
\hline Employed & $33.5(29.2-38.2)$ & $47.6(46.6-48.7)$ & \\
\hline Unemployed & $66.5(61.8-70.8)$ & $52.4(51.3-53.4)$ & \\
\hline Smoker & & & 0.033 \\
\hline Never smoker & $91.6(89.0-93.6)$ & $88.2(87.5-88.9)$ & \\
\hline Former smoker & $2.3(1.4-4.0)$ & $2.8(2.5-3.2)$ & \\
\hline Current smoker & $6.1(4.4-8.4)$ & $9.0(8.4-9.6)$ & \\
\hline Alcohol intake & & & $<0.001$ \\
\hline$\geq 1$ time/mo & $22.2(18.7-26.2)$ & $37.7(36.7-38.7)$ & \\
\hline$<1$ time/mo & $77.8(73.8-81.3)$ & $62.3(61.3-63.3)$ & \\
\hline Comorbidities & & & $<0.001$ \\
\hline No comorbidity & $44.1(39.3-49.0)$ & $62.1(61.0-63.2)$ & \\
\hline$\geq 1$ comorbidity & $55.9(51.0-60.7)$ & $37.9(36.8-39.0)$ & \\
\hline Time since diagnosis (y) & $7.24 \pm 0.5$ & & $<0.001$ \\
\hline$<5$ & $47.2(42.6-51.8)$ & - & \\
\hline $5-10$ & $23.5(20.0-27.4)$ & - & \\
\hline$>10$ & $27.3(25.3-33.7)$ & - & \\
\hline
\end{tabular}

Values are presented as mean \pm standard error or $\%$ (95\% confidence interval). *Obtained by chi-square test. 
stroke, angina, myocardial infarction, osteoarthritis, rheumatic arthritis, asthma, renal insufficiency, hepatitis B or C, diabetes, or liver cirrhosis, as determined by a doctor's diagnosis. The time since cancer diagnosis in the survivor group was classified into 3 groups; less than 5 years, $5-10$ years, or more than 10 years.

\section{Statistical Analyses}

The general characteristics and prevalence of breast and cervical cancer screening were compared between cancer survivors and the noncancer controls using a chi-square test. Differences in cancer screening rates were compared according to cancer site: thyroid, stomach, colon, breast, and cervix. We excluded the mammogram in breast cancer survivors and the Papanicolaou test in cervix cancer survivors. The analysis consisted of a one-way analysis of variance with a post hoc Dunnett test. Multiple logistic regression analysis was used to investigate factors associated with cancer screening behavior after adjusting for age, marital status, education level, household income, employment, smoking, alcohol use, and comorbidities. All analyses were conducted using IBM SPSS ver. 21.0 software (IBM Corp., Armonk, NY, USA), taking sampling weights and the complex survey design into consideration. We considered P-values less than 0.05 to be statistically significant.

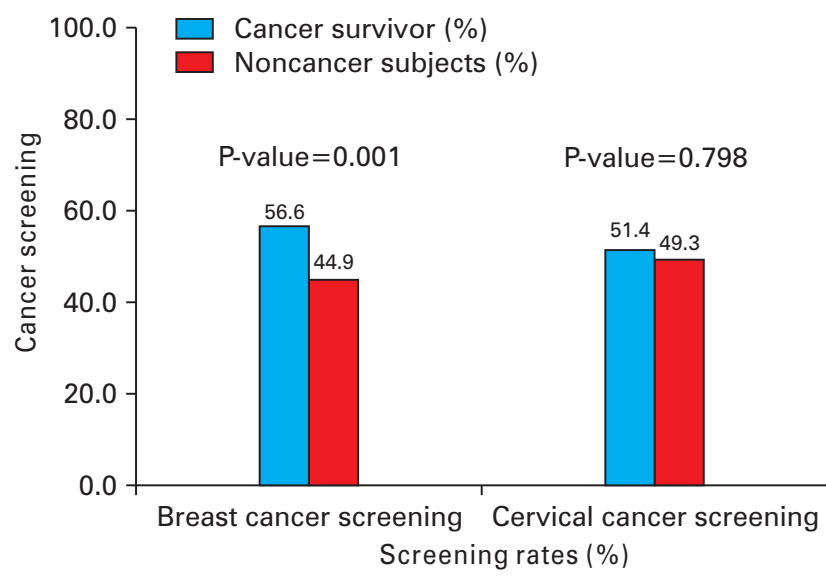

Figure 1. The rate of cancer screening between women cancer survivors and noncancer group.

\section{RESULTS}

The general characteristics of the 738 cancer survivors and 17,027 noncancer controls are shown in Table 1. Cancer survivors were older and had lower levels of education, household income, and employment compared to the non-cancer controls. The cancer survivors were less likely to smoke and drink alcohol and had more comorbidities than the non-cancer controls.

The cancer screening rates of the cancer survivors and non-cancer controls are shown in Figure 1. The cancer survivor group was significantly more likely to have breast cancer screening than the non-cancer controls (56.6\% versus $44.9 \%, \mathrm{P}=0.001$ ). However, cervical cancer screening practices were not significantly different between cancer survivors and women in the non-cancer control group (51.4\% versus 49.3\%, $\mathrm{P}=0.798$ ). Multiple regression analysis after adjusting for sociodemographic factors showed similar results (Table 2).

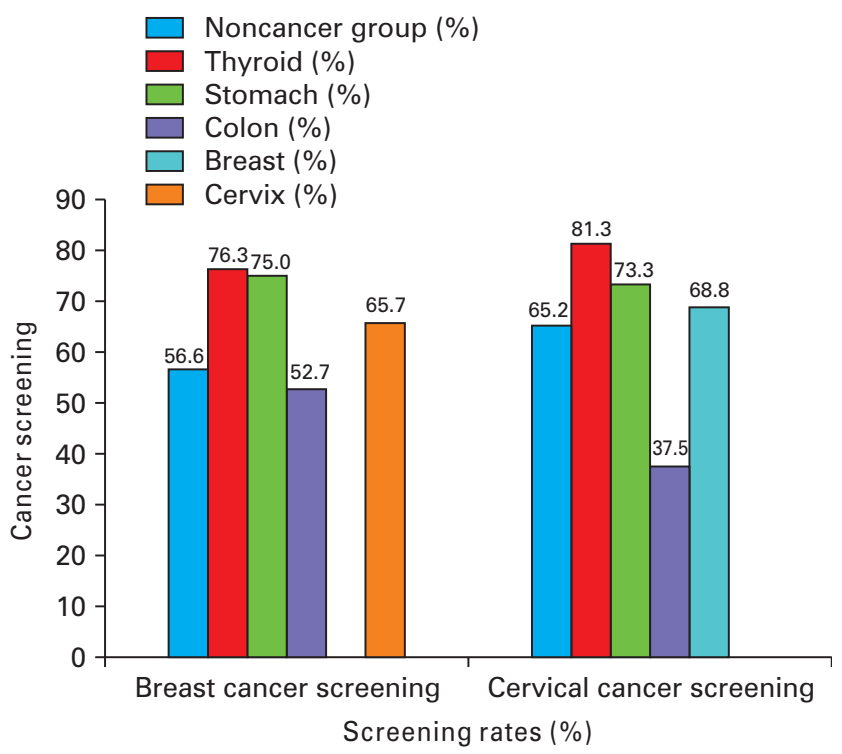

Figure 2. The difference of cancer screening rate according to cancer site. Breast and cervical cancer screening in 2 years. P-values in breast cancer screening were $0.014,0.045,0.802,0.280$ for thyroid, stomach, colon, cervix cancer survivors, compared to noncancer subjects. P-values in cervical cancer screening were 0.020 , $0.343,0.007,0.613$ for thyroid, stomach, colon, breast cancer survivors, compared to noncancer subjects.

Table 2. Odds ratio between female cancer survivors and non-cancer controls undergoing mammography or a Papanicolaou smear test

\begin{tabular}{|c|c|c|c|c|}
\hline \multirow{2}{*}{ Population } & \multicolumn{2}{|c|}{ Mammography* } & \multicolumn{2}{|c|}{ Papanicolaou smear test ${ }^{\dagger}$} \\
\hline & Crude OR (95\% Cl) & Adjusted OR (95\% Cl) & Crude OR (95\% Cl) & Adjusted OR (95\% Cl) \\
\hline Non-cancer controls & 1.00 & 1.00 & 1.00 & 1.00 \\
\hline Cancer survivor & $1.97(1.34-2.88)$ & $1.75(1.12-2.73)$ & $1.10(0.80-1.52)$ & $1.20(0.84-1.72)$ \\
\hline P-value $e^{\ddagger}$ & 0.001 & 0.010 & 0.549 & 0.330 \\
\hline
\end{tabular}

The analysis was limited to examinations taking place within two years. The analysis was adjusted for age, marital status, education, income, employment, smoking, alcohol status, and comorbidities.

$\mathrm{OR}$, odds ratio; $\mathrm{Cl}$, confidence interval.

*Except for breast cancer survivors among female cancer survivors ( $\mathrm{N}=584)$. ${ }^{\dagger}$ Except for cervical cancer survivors among female cancer survivors ( $\left.\mathrm{N}=592\right)$. ${ }^{\ddagger} 0 \mathrm{btained}$ by multiple logistic regression analysis. 
Table 3. Cancer screening behavior according to time since diagnosis

\begin{tabular}{|c|c|c|c|c|}
\hline \multirow{2}{*}{ Time since diagnosis } & \multicolumn{2}{|c|}{ Mammography* } & \multicolumn{2}{|c|}{ Papanicolaou smear test $^{\dagger}$} \\
\hline & Crude OR $(95 \% \mathrm{Cl})$ & Adjusted OR (95\% Cl) & Crude OR $(95 \% \mathrm{Cl})$ & Adjusted OR $(95 \% \mathrm{Cl})$ \\
\hline$<5 y$ & 1.00 & 1.00 & 1.00 & 1.00 \\
\hline $5-10 y$ & $1.39(0.57-3.40)$ & $1.88(0.75-4.70)$ & $0.51(0.23-1.13)$ & $0.61(0.25-1.47)$ \\
\hline$\geq 10 y$ & $1.27(0.56-2.88)$ & $1.60(0.61-4.23)$ & $0.27(0.12-0.62)$ & $0.28(0.11-0.75)$ \\
\hline P-value $e^{\ddagger}$ & 0.11 & 0.112 & 0.012 & 0.045 \\
\hline
\end{tabular}

The analysis was limited to examinations taking place within two years. The analysis was adjusted for age, marital status, education, income, employment, smoking, alcohol status, and comorbidities.

$\mathrm{OR}$, odds ratio; $\mathrm{Cl}$, confidence interval.

${ }^{\star}$ Except for breast cancer survivors among female cancer survivors ( $\left.N=584\right)$. ${ }^{\dagger}$ Except for cervical cancer survivors among female cancer survivors ( $\left.N=592\right)$. ${ }^{\ddagger} 0$ btained by oneway analysis of variance with the Dunnett test used in post hoc analysis.

Differences in cancer screening rates according to the most common cancer sites in Korean women are shown in Figure 2. Thyroid and stomach cancer survivors had higher rates of breast cancer screening than women in the non-cancer control group. Thyroid cancer survivors also had higher screening rates than cervical cancer survivors. Colon cancer survivors had lower screening rates for cervical cancer than women in the non-cancer control group.

The rate of cancer screening evaluated according to the time since diagnosis is shown in Table 3. In terms of breast cancer screening, cancer survivors showed no significant difference in screening rates five years after their cancer diagnosis. However, cancer survivors were less likely to have cervical cancer screening 10 years after their cancer diagnosis.

The factors associated with cancer screening behavior in the cancer survivors are shown in Table 4 . Only women over 40 years of age had significantly higher breast cancer screening rates.

\section{DISCUSSION}

In this study, women in a cancer-survivors group were more likely to undergo breast cancer screening than women in a non-cancer control group. Nonetheless, half of the cancer survivors did not undergo cancer screening. There were no sociodemographic factors or health behaviors that were significantly associated with breast and cervical cancer screening, with the exception of having an age over 40 years, which was positively associated with breast cancer screening.

We propose several reasons for the low rate of cancer screening in female cancer survivors. First, cancer survivors believe that cancer screening is not necessary because they have routine medical examinations. ${ }^{13,16)}$ Second, there is a lack of physician recommendations about SPC screening. Past studies on perceptions and attitudes about SPC screening among Korean cancer survivors have shown that cancer survivors have positive attitudes towards SPC screening, even though most do not receive cancer screening. ${ }^{13,17)}$ A study of women without cancer in Korea found that the most common reasons for not participating in cancer screening programs were 'not feeling the need' and 'not having time.' ${ }^{18)}$ However, cancer survivors perceive themselves as having a greater risk of developing SPC, ${ }^{10,13,17)}$ and they visit health care providers more frequently than the general population. ${ }^{19-21)}$
These factors may affect SPC screening rates. Also, in previous studies, cancer survivors followed up by both primary care providers and oncologists were more likely to have SPC screening and other comprehensive care compared to those who were only seen by oncologists. ${ }^{22,23)}$ Thus, we think that the role of primary care providers for following cancer survivors is important in improving SPC screening rates.

Comparing breast and cervical cancer screening rates according to cancer site, our results revealed that stomach and thyroid cancer survivors had greater than $70 \%$ screening rates for breast and cervical cancers. However, of colon cancer survivors, only $52.7 \%$ had breast cancer screening and $37.5 \%$ had cervical cancer screening, which was lower than the rates in non-cancer controls. These findings were consistent with previous studies. ${ }^{13,20,24)}$ However, in previous studies, the much lower rate of SPC screening for female colon cancer survivors was noted as a weak point of their health care and promotion policy. Survivors of breast and cervical cancer were expected to have higher rates of screening with mammograms and Papanicolaou testing, respectively, because of the common hormone receptors underlying the pathogenesis of both diseases. However, the screening rates in these groups were not different from those of the non-cancer controls or survivors of cancers at other sites. Therefore, patient education and physicians' recommendations are needed for these patient populations.

Our findings suggest that sociodemographic factors and health behaviors are not significantly associated with breast and cervical cancer screening rates in female cancer survivors. In a previous study, cancer survivors with high household incomes were more likely to undergo cancer screening than those with low household incomes. ${ }^{8)}$ We propose that people in the middle range of household incomes may have more easy access to the NCSP. Since 2005, the NCSP has been free for Medical Aid recipients and National Health Insurance participants in the lower half of the income stratum. ${ }^{25)}$ The NCSP might have reduced the effect of household income on cancer screening practices. Other studies on breast and cervical cancer screening in the general population show that it is associated with education level, marital status, ${ }^{18,26)}$ smoking, ${ }^{27)}$ and alcohol use. ${ }^{28)}$ However, our results indicate that the marital status, education level, smoking, and alcohol use of female cancer survivors were not significantly associated with cancer screening rates. 
Table 4. Factors associated with cancer screening behavior in cancer survivors

\begin{tabular}{|c|c|c|}
\hline \multirow[b]{2}{*}{ Variable } & \multicolumn{2}{|c|}{ Cancer survivor } \\
\hline & Mammography* & $\begin{array}{l}\text { Papanicolaou } \\
\text { smear test }^{\dagger}\end{array}$ \\
\hline \multicolumn{3}{|l|}{ Age $(y)$} \\
\hline $30-39$ & 1.00 & 1.00 \\
\hline $40-49$ & $7.55(1.68-33.95)$ & $2.20(0.28-17.12)$ \\
\hline $50-59$ & $14.73(2.85-76.21)$ & $2.72(0.34-22.81)$ \\
\hline$\geq 60$ & $10.86(1.79-65.96)$ & $0.88(0.10-7.43)$ \\
\hline P-value for trend $d^{\ddagger}$ & 0.01 & 0.132 \\
\hline \multicolumn{3}{|l|}{ Marital status } \\
\hline Married & 1.00 & 1.00 \\
\hline Divorced/separated/single & $0.87(0.28-2.66)$ & $2.52(0.96-5.89)$ \\
\hline P-value for trend $d^{\ddagger}$ & 0.96 & 0.097 \\
\hline \multicolumn{3}{|l|}{ Education } \\
\hline$<$ High school & 1.00 & 1.00 \\
\hline High school & $3.13(0.84-11.69)$ & $1.99(0.72-5.50)$ \\
\hline$\geq$ College & $5.11(0.72-36.13)$ & $0.99(0.20-4.81)$ \\
\hline P-value for trend $d^{\ddagger}$ & 0.017 & 0.554 \\
\hline \multicolumn{3}{|l|}{ Quartile of household income } \\
\hline Q1 & 1.00 & 1.00 \\
\hline Q2 & $5.03(1.58-16.01)$ & $2.48(0.88-6.98)$ \\
\hline Q3 & $6.07(1.50-24.51)$ & $7.16(2.01-25.58)$ \\
\hline Q4 & $1.51(0.48-4.77)$ & $4.65(1.50-14.46)$ \\
\hline$P$-value for trend $d^{\ddagger}$ & 0.06 & 0.105 \\
\hline \multicolumn{3}{|l|}{ Employment } \\
\hline Employed & 1.00 & 1.00 \\
\hline Unemployed & $0.97(0.41-2.28)$ & $0.84(0.36-1.97)$ \\
\hline P-value for trend $d^{\ddagger}$ & 0.807 & 0.904 \\
\hline \multicolumn{3}{|l|}{ Smoking } \\
\hline Never smoker & 1.00 & 1.00 \\
\hline Former smoker & $0.84(0.08-9.37)$ & $0.50(0.11-2.12)$ \\
\hline Current smoker & $0.52(0.04-6.52)$ & $2.42(0.22-26.53)$ \\
\hline P-value for trend ${ }^{\ddagger}$ & 0.951 & 0.802 \\
\hline \multicolumn{3}{|l|}{ Alcohol drinking } \\
\hline$<1$ time/mo & 1.00 & 1.00 \\
\hline$\geq 1$ time/mo & $0.82(0.26-2.62)$ & $0.49(0.17-1.40)$ \\
\hline P-value for trend ${ }^{\ddagger}$ & 0.121 & 0.374 \\
\hline \multicolumn{3}{|l|}{ Comorbidity } \\
\hline No comorbidity & 1.00 & 1.00 \\
\hline$\geq 1$ comorbidity & $1.28(0.51-3.19)$ & $0.36(0.15-0.89)$ \\
\hline P-value for trend ${ }^{\ddagger}$ & 0.690 & 0.089 \\
\hline
\end{tabular}

Values are presented as adjusted odds ratio ( $95 \%$ confidence interval). The analysis was limited to examinations taking place within two years.

${ }^{*}$ Except for breast cancer survivors among female cancer survivors ( $\left.N=584\right) .{ }^{~}$ Except for cervical cancer survivors among female cancer survivors $(\mathrm{N}=592)$. ${ }^{\ddagger}$ Obtained by multiple logistic regression analysis after adjusting for age, marital status, education, income, employment, smoking, alcohol status, and comorbidities.

Generally, the rate of SPC screening declines with time since the primary cancer diagnosis. ${ }^{13,24,29)}$ Accordingly, the cancer survivors in our study surviving more than 10 years after their cancer diagnosis were less likely to undergo cervical cancer screening, which was thought to be due to the fact that they were too old to undergo routine cervical cancer screening. However, for breast cancer screening, we found no decrease in screening rates with time.

This study had several strengths. We excluded breast and cervical cancer survivors for our overall analysis to rule out their influence on overall cancer screening rates; therefore, our data reflect a representative sample of the general population in Korea.

A limitation of this study was the use of secondary data. KNHANES did not provide clinical data such as cancer stage and the method of cancer treatment. Also, we could not explain the causal relationship between cancer screening rates and sociodemographic factors because the study design was cross-sectional. KNHANES is based on self-reported questionnaires, introducing the possibility of recall bias. However, in the self-reported data, both cancer screening paid for by the government and screening paid for by individuals can be included in the analysis of screening behavior.

In conclusion, a substantial proportion of women cancer survivors do not undergo breast and cervical cancer screening. However, unlike previous studies, sociodemographic factors showed no significant effects on screening rates. We need to comprehensively understand other factors that affect SPC screening behavior in female cancer survivors such as their knowledge and the perceptions of both cancer survivors and physicians.

\section{CONFLICT OF INTEREST}

No potential conflict of interest relevant to this article was reported.

\section{REFERENCES}

1. Jung KW, Won YJ, Kong HJ, Oh CM, Cho H, Lee DH, et al. Cancer statistics in Korea: incidence, mortality, survival, and prevalence in 2012. Cancer Res Treat 2015;47:127-41.

2. Yabroff KR, Lawrence WF, Clauser S, Davis WW, Brown ML. Burden of illness in cancer survivors: findings from a population-based national sample. J Natl Cancer Inst 2004;96:1322-30.

3. Dong C, Hemminki K. Second primary neoplasms in 633,964 cancer patients in Sweden, 1958-1996. Int J Cancer 2001;93:155-61.

4. Travis LB. The epidemiology of second primary cancers. Cancer Epidemiol Biomarkers Prev 2006;15:2020-6.

5. Bellizzi KM, Rowland JH, Jeffery DD, McNeel T. Health behaviors of cancer survivors: examining opportunities for cancer control intervention. J Clin Oncol 2005;23:8884-93.

6. Corkum M, Hayden JA, Kephart G, Urquhart R, Schlievert C, Porter G. Screening for new primary cancers in cancer survivors compared to non-cancer controls: a systematic review and meta-analysis. J Cancer Surviv 2013;7:455-63.

7. Trask PC, Rabin C, Rogers ML, Whiteley J, Nash J, Frierson G, et al. Cancer screening practices among cancer survivors. Am J Prev Med 2005;28:351-6.

8. Cho J, Guallar E, Hsu YJ, Shin DW, Lee WC. A comparison of cancer screening practices in cancer survivors and in the general population: the Korean national health and nutrition examination survey (KNHANES) 2001-2007. Cancer Causes Control 2010;21:2203-12.

9. Corkum M, Urquhart R, Kephart G, Hayden JA, Porter G. Breast and cervical cancer screening behaviours among colorectal cancer survivors in Nova Scotia. Curr Oncol 2014;21:e670-7.

10. Park SM, Park CT, Park SY, Bae DS, Nam JH, Cho CH, et al. Factors re- 
lated to second cancer screening practice in disease-free cervical cancer survivors. Cancer Causes Control 2009;20:1697-703.

11. National Cancer Center. Cancer facts and figures 2015. Goyang: National Cancer Center; 2015.

12. Han MA, Choi KS, Park JH, Moore MA, Park EC. Midcourse evaluation of the second-term 10-year plan for cancer control in Korea. Asian Pac J Cancer Prev 2011;12:327-33.

13. Shin DW, Kim YW, Oh JH, Kim SW, Chung KW, Lee WY, et al. Knowledge, attitudes, risk perception, and cancer screening behaviors among cancer survivors. Cancer 2011;117:3850-9.

14. Korea Centers for Disease Control and Prevention. The fourth Korea National Health and Nutrition Examination Survey guide book (KNHANES IV 2007-2009). Cheongju: Korea Centers for Disease Control and Prevention; 2007-2009.

15. Korea Centers for Disease Control and Prevention. The fifth Korea National Health and Nutrition Examination Survey guide book (KNHANES V 2010-2012). Cheongju: Korea Centers for Disease Control and Prevention; 2010-2012.

16. Shin DW, Baik YJ, Kim YW, Oh JH, Chung KW, Kim SW, et al. Knowledge, attitudes, and practice on second primary cancer screening among cancer survivors: a qualitative study. Patient Educ Couns 2011;85:74-8.

17. Yang YH. A path analysis on factors influencing second primary cancer screening practices in stomach, colon, and breast cancer survivors. J Korean Acad Nurs 2014;44:139-48.

18. Park MJ, Park EC, Choi KS, Jun JK, Lee HY. Sociodemographic gradients in breast and cervical cancer screening in Korea: the Korean National Cancer Screening Survey (KNCSS) 2005-2009. BMC Cancer 2011;11:257.

19. Grunfeld E, Hodgson DC, Del Giudice ME, Moineddin R. Populationbased longitudinal study of follow-up care for breast cancer survivors.
J Oncol Pract 2010;6:174-81.

20. Grunfeld E, Moineddin R, Gunraj N, Del Giudice ME, Hodgson DC, Kwon JS, et al. Cancer screening practices of cancer survivors: population-based, longitudinal study. Can Fam Physician 2012;58:980-6.

21. Kwon JS, Elit L, Saskin R, Hodgson D, Grunfeld E. Secondary cancer prevention during follow-up for endometrial cancer. Obstet Gynecol 2009;113:790-5.

22. Earle CC, Neville BA. Under use of necessary care among cancer survivors. Cancer 2004;101:1712-9.

23. Snyder CF, Earle CC, Herbert RJ, Neville BA, Blackford AL, Frick KD. Preventive care for colorectal cancer survivors: a 5-year longitudinal study. J Clin Oncol 2008;26:1073-9.

24. Suh B, Shin DW, Kim SY, Park JH, Chang WY, Lim SP, et al. Mode of primary cancer detection as an indicator of screening practice for second primary cancer in cancer survivors: a nationwide survey in Korea. BMC Cancer 2012;12:557.

25. Suh M, Choi KS, Park B, Lee YY, Jun JK, Lee DH, et al. Trends in cancer screening rates among Korean men and women: results of the Korean National Cancer Screening Survey, 2004-2013. Cancer Res Treat 2016;48:1-10.

26. Katz SJ, Hofer TP. Socioeconomic disparities in preventive care persist despite universal coverage: breast and cervical cancer screening in Ontario and the United States. JAMA 1994;272:530-4.

27. Welch C, Miller CW, James NT. Sociodemographic and health-related determinants of breast and cervical cancer screening behavior, 2005. J Obstet Gynecol Neonatal Nurs 2008;37:51-7.

28. Choi KH, Heo J, Kim S, Jeon YJ, Oh M. Factors associated with breast and cervical cancer screening in Korea: data from a national community health survey. Asia Pac J Public Health 2013;25:476-86.

29. Park JK, Park HA. Screening rates of major cancers after a cancer diagnosis in adults in Korea. Korean J Health Promot 2012;12:67-74. 